\title{
Impact of Graphene and Hot-Rolling on the Microstructure and Mechanical Properties of Aluminum Matrix Nano-Composite
}

\section{T. El-Bitar}

Metal Working Department

F. Nouh

Sinai University

Omayma A. El-Kady ( $\sim$ o.alkady68@gmail.com )

Manufacturing Technology institute

Hossam M. Yehia

Helwan University

\section{Research Article}

Keywords: Powder metallurgy, Hot rolling, Graphene, Density, compressive strength, wear rate

Posted Date: February 1st, 2022

DOI: https://doi.org/10.21203/rs.3.rs-1258597/v1

License: (a) (i) This work is licensed under a Creative Commons Attribution 4.0 International License. Read Full License 


\section{Abstract}

Due to the low density of aluminum, it has become the first choice of materials for designers. Aluminum is also characterized by high specific strength. It still suffers from inferior mechanical properties, such as its high ductility, limiting its use in industry in the pure state. In this research, trials to improve the mechanical properties of aluminum by maintaining its low density. It was the first choice among materials to improve aluminum's mechanical and physical properties. Because of the importance of graphene resulting from its low density and unique properties as a newly discovered material, researchers tried to study its effect in various fields. Using the method of powder metallurgy followed by the hot rolling as a secondary process, aluminum composites reinforced with 10\% copper, $2.5 \%$ alumina, and different weight ratios of graphene up to $1.5 \%$ were manufactured. The components were mixed for 45 hours in the presence of 5\% hexane as a PCA by mechanical alloy milling using $12 \mathrm{~mm}$ balls and a 10:1 ball to powder ratio. The appropriate pressure, temperature, and sintering time were determined for the manufacture by the powder metallurgy method. The results by powder metallurgy method showed a general improvement in the microstructure and physicomechanical properties up to $1 \%$ graphene. Still, the results deteriorated at $1.5 \%$ due to the presence of some accumulations of graphene. By conducting the hot rolling process, all results exceeded their counterparts by the powder metallurgy method and improved up to $1.5 \%$. In general, the microstructure in both cases before and after the hot rolling was ideal.

\section{Introduction}

In the last few years, the strength-to-weight ratio property has become an important material selection parameter in many industrial applications, especially in aircraft, aerospace, automobiles, and various other fields. Aluminum metal is one of the most important materials used in these applications because it has a low density of $2.7 \mathrm{~g} / \mathrm{cm}^{3}$ that makes it has a high specific strength ratio. However, it is still criticized for its low mechanical properties, higher coefficient of thermal expansion, and poor tribological properties. Reinforcing aluminum with copper improves its properties and reduces its specific strength that restricts its applications in lightweight constructions. To enhance the specific strength property of Al$\mathrm{Cu}$, authors thought to reinforce it with nano-graphene layers. Because of the high strength of covalent bonds between carbon atoms and low density of graphene that is $2.26 \mathrm{~g} / \mathrm{cm}^{3}$, it has a very high specific strength that makes it the suitable material for this aim. The load transfer effect of graphene due to the large specific area introduces a better strengthening efficiency than nanoscale ceramic reinforcements [1-3].

Many researchers were interested in studying the effect of graphene nano-sheets on the properties of aluminum matrix composites. The uniform dispersion and wetting of the graphene with the aluminum matrix were the significant challenges, where the graphene clusters tend to deteriorate the mechanical properties of the aluminum composite. The effect of graphene with 1,3 , and $5 \mathrm{wt} \%$ on the mechanical properties of aluminum by spark plasma sintering has been studied. The predetermined reduced graphene oxide percentages were wet-blended with 7055 aluminum powders in an acetone solution in an 
ultrasonic bath for $4 \mathrm{~h}$. The SPS experiments were performed at $400^{\circ} \mathrm{C}$ under vacuum with a 1 min dwell time. The results showed that the Vickers hardness was increased from Hv 131.5 for 7055 aluminum alloy to $\mathrm{Hv} 151.2$ for the $\mathrm{Al} / 1 \mathrm{wt} \%$ graphene plates and decreased to Hv 98.6 at $5 \mathrm{wt} \%$. Agglomerations and coalescence of the graphene plates become more severe at higher contents. The composite with an addition of $1 \mathrm{wt} \%$ graphene significantly improves the mechanical properties. The yield and compressive strength increase by $34.9 \%$ and $22.1 \%$, respectively, compared to pure 7055 aluminum alloy [4].

Aluminum matrix composites with different amounts of exfoliated graphite nano-layers were fabricated by the powder metallurgy method. The mixed powders have been cold pressed at $520 \mathrm{MPa}$ for $5 \mathrm{~min}$ followed by sintering at $600^{\circ} \mathrm{C}$ for $6 \mathrm{~h}$. The hardness, strength, and corrosion behavior (in $3.5 \% \mathrm{NaCl}$ solution) have been studied. The maximum strength, Vickers hardness, and corrosion rate of Al were increased by increasing the exfoliated graphite content, while the presence of exfoliated graphite with Al activates its galvanic corrosion [5].

The effect of homogeneously distributed GNPs as a long-term corrosion inhibitors on the aluminum corrosion behavior has been investigated. The deformation-driven metallurgy technique was applied to prepare Al/1.5 GNP composites at different rotational speeds. The process could effectively obtain grain refinement and good dispersion of GNPs via severe plastic deformation. Due to the high homogenous distribution and the formation of protective oxide film, a higher corrosion resistance was established [6].

Many methods were used to manufacture aluminum composites and alloys, including casting and extrusion. However, those methods are not suitable for all composite materials. For example, it is very difficult to add graphene to aluminum by casting method, where it has a lightweight $\left(2.2 \mathrm{~g} / \mathrm{cm}^{3}\right)$ and difficult to be distributed homogeneously in the molten aluminum and can float to the surface easily. One of the best techniques suggested to solve this problem is the powder metallurgy technique; as it is possible to mix lightweight materials with a heavier one easily, and form them in a green compacted to the appropriate shape, then sintering them to be suitable for using in industrial applications. The production of lightweight composites is not the only obstacle, but also addition of nano-metric materials in a high percentage is the biggest challenge, as addition of nano-metric materials in large quantities eventually leads to the production of defects such as accumulations, which have a very large negative impact on the properties of the manufactured materials. Hence, the idea of working in this research is how to add a nano-metric ceramic materials in large quantities with a good homogeneity and good cohesion with the metal matrix, to ensure the improvement of the physical and mechanical properties of the materials intended to be manufactured. The solution to such a problem will established by producing these composites under optimal conditions by the metallurgical powder method, then using secondary forming processes such as rolling.

Rolling is a secondary forming process that performs on either cold or hot by passing metal blocks between two rolls to reach the required shape and thickness. It is used for producing strips, sheets, and foils. Hot rolling is one of the most critical thermoforming methods for metal matrix composites. It is performed at a temperature known as the recrystallization temperature of nearly $0.35 \mathrm{~T}$. During the hot 
rolling, the strain hardening phenomenon is dissipated, and the metal plasticity is easy; consequently, a high deformation percentage can be achieved. However, there are limited studies devoted to researching the hot rolling behavior of graphene/metal composites by powder metallurgy.

The effect of hot rolling process on the porosity, hardness, tensile strength, and distribution of fly ash in the $\mathrm{Al}-4.5 \% \mathrm{Cu}$ cast alloy was investigated. An $80 \%$ reduction without edge cracking was successfully achieved. The hardness and tensile strength of rolled composites gradually increased with an increase in rolling reduction. On the other hand, Porosity was decreased by increasing reduction percentage. The optical micrograph of the structure indicates refining of grains and uniform distribution of fly ash particles by increasing the rolling reduction [7].

This work studies the effect of graphene content up to 1.5 by 0.5 intervals on the physical and mechanical properties of the $\mathrm{Al}-10 \mathrm{Cu} / 2.5 \mathrm{Al}_{2} \mathrm{O}_{3}$ nanocomposites prepared by powder metallurgy followed by hot rolling processes.

\section{Experimental Work 2.1 Materials}

Three different raw powder materials, namely aluminum with 2-3 $\mu \mathrm{m}$ particle size and 99.9 purity (Loba Chemie Pvt. Ltd., India), nano $\mathrm{Al}_{2} \mathrm{O}_{3}$ powder with purity of $99.97 \%$ and particle size of $50-100 \mathrm{~nm}$ (Hart Minerals), and graphene strips with 2-10 nm thickness (ACS Material, LLC (an advanced chemical supplier)), were purchased to fabricate aluminum matrix composite. The sodium hydroxide, acetone, silver nitrate, $33 \%$ ammonia, $28 \%$ formaldehyde were supplied for ceramic powder cleaning and metallization. The hexane liquid was supplied for lubricating and as a process control agent during the mixing process. All chemicals were purchased from El-Nasr Chemicals Company Cairo - Egypt.

\subsection{Sample Fabrication}

The surface of the nano-alumina and graphene nano-sheets were treated to remove any contamination by stirring in a $10 \%$ sodium hydroxide solution and acetone for 1 hour, respectively. Next, both of them are coated with $5 \% \mathrm{Ag}$ by the electroless coating process to improve their wettability and adhesion with the aluminum matrix [8]. Six samples, namely pure Al, Al/10 wt\% Cu, Al-10 wt\% Cu/2.5 wt\% $\mathrm{Al}_{2} \mathrm{O}_{3}$, and different GNs which are $0.5,1,1.5 \mathrm{wt} \%$, were prepared by mechanical mixing in a $5 \%$ hexane liquid to prevent accumulation of the different powders. The mechanical alloy milling process was continued for $45 \mathrm{hrs}$ to ensure excellent distribution of the mixture and reduction of the particles size of the aluminum and copper particles. The ball to powder ratio was 10:1 and the alumina ball diameter was $12 \mathrm{~mm}$.

A hydraulic press and circular bore die with a diameter of (10 and $7 \mathrm{~mm})$ were used to prepare the green samples. Some pressures were tested to determine the optimal pressure. The suitable pressure was 600 $\mathrm{MPa}$ and the height of the green samples was $15 \mathrm{~mm}$. After that, all the green samples were sintered in a vacuum furnace at $560^{\circ} \mathrm{C}$ for 60 minutes, as shown in Figure 1. The sintering cycle was as follows; the 
samples were heated to $250^{\circ} \mathrm{C}$ for 15 minutes to ensure a uniform temperature distribution during heating, removal of all hexane liquid from the samples, and expel any gases. The temperature was raised to 550,565 , and $580^{\circ} \mathrm{C}$ for 60 minutes holding time with an increment rate of $2^{\circ} \mathrm{C} / \mathrm{min}$. Two groups of samples have been prepared.

After the powder metallurgy fabrication route, the samples were prepared for the hot rolling process. This step aims at investigating the rolling process's effect on the microstructure and properties of fabricated powder metallurgy nanocomposites.

Six aluminum holders were prepared to fix the fabricated nanocomposite for the rolling process. All holders were bored with $10 \mathrm{~mm}$, and samples were fixed, as shown in Figure 2.

The samples were heated at $480^{\circ} \mathrm{C}$ for $15 \mathrm{~min}$ in an electric oven then rolled with $45 \mathrm{rpm}$ speed. The rolls were made of steel with a diameter of $200 \mathrm{~mm}$. The reduction ratio was $3.5 \% \mathrm{~mm} /$ cycle and the total reduction ratio was $35 \%$. After each cycle, samples were reheated to maintain the rolling temperature. During the rolling process, the rolls were heated by inserting a heated aluminum piece between them several times before rolling the samples directly to avoid the rapid drop of the sample temperature during the deformation process.

\subsection{Sample Characterization}

Archimedes' method was used to measure the density of the fabricated nanocomposites using distilled water as a floating liquid according to MPIF 42, 1998 standards. The sintered samples were weighed in air and distilled water. Silicon carbide (SiC) sheet papers of grade E800, 1000, 2000, 2500, and 3000, respectively, were used for samples' surface preparation.

Grinding samples were refined using diamond paste. The back-scattering scanning electron microscope SEM-BSC Quanta FEG250 model was used to investigate the microstructure of the fabricated and rolled nanocomposites.

The bulk hardness was measured using the Vickers 5030 SKV England hardness tester. Measurements parameters were $5 \mathrm{~kg}$ load for $15 \mathrm{sec}$ download time. An average of six penetration readings of each hardness value before and after rolling were calculated.

The cold compression test was performed to evaluate the maximum and yield stress of the fabricated and rolled nanocomposites. The lengths to diameter ratio of the tested samples was $L / D$ ratio $>0.8$. The test was carried out at $60 \%$ of the sample length. The UH F500KN universal testing machine was used to perform the test. The applied cross velocity used in this study is $1 \mathrm{~mm} / \mathrm{min}$.

The fabricated nanocomposites wear rate was investigated using a pin on the disc wear test machine at 5 and 10 loads and different rotational speeds of 200,300, and $400 \mathrm{rpm}$ for $10 \mathrm{~min}$. Before each sample test, the sample and disc surfaces were polished with $\mathrm{Ra}=0.25 \mu \mathrm{m}$. All tests were established at room temperature, and no lubricant material was used. 


\section{Results And Discussion \\ 3.1 Powder characterization}

The SEM and EDX analyses were performed to study morphology and chemical composition of the asreceived raw powder materials and $1.5 \mathrm{wt} \% \mathrm{GNs}$ sample after the mechanical milling process (Figure 3). Semispherical, dendritic, and flake shapes are observed for $\mathrm{Al}, \mathrm{Cu}$, and GNs, respectively. The EDX analysis confirmed the used raw materials purity, and no new other elements were detected, which means reasonable milling environment control. Also, good distribution all of them is confirmed due to the good mechanical milling process conditions.

\subsection{Density measurements}

Figure 4 shows the relative density of the fabricated nanocomposites by powder metallurgy at elevated temperatures and after the rolling process at the optimum sintering conditions. The results show that the relative density was improved by raising the sintering temperature from $550^{\circ} \mathrm{C}$ to $565^{\circ} \mathrm{C}$ then decreasing at $580^{\circ} \mathrm{C}$. The lowest values of the relative density were achieved at $550^{\circ} \mathrm{C}$, which wasn't sufficient to close the porosity and establish the complete adhesion between the neighbor particles with each other. Due to $\mathrm{Cu}$ and $\mathrm{Al}_{2} \mathrm{O}_{3}$ reinforcements, partial melting of aluminum and sample swelling was observed at $580^{\circ} \mathrm{C}$. The swelling may be due to sintering the surface before the core of the material, which leads to entrapped gases inside the sample and consequently porosities formed. The most significant improvement in samples density is observed at $565^{\circ} \mathrm{C}$. In general, the relative density is improved by reinforcing the $\mathrm{Al}$ matrix with $10 \mathrm{wt} \% \mathrm{Cu}$ then decreasing by adding $2.5 \mathrm{wt} \%$ nano- $\mathrm{Al}_{2} \mathrm{O}_{3}$ and different percentages of graphene nano-sheets. Raising or reducing the relative density depends on the density of the reinforcement material where the Cu has $8.9 \mathrm{~g} / \mathrm{cm}^{3}$ that is greater than that of Al with $2.7 \mathrm{~g} / \mathrm{cm}^{3}$, so the density was increased by the addition of $\mathrm{Cu}$. On the other hand, the graphene has $2.2 \mathrm{~g} / \mathrm{cm}^{3}$ that is less dense than the density of $\mathrm{Al}_{\text {and }} \mathrm{Al}_{2} \mathrm{O}_{3}\left(3.93 \mathrm{~g} / \mathrm{cm}^{3}\right)$, so that the allover density is decreased. The decreasing in density of graphene reinforced aluminum nano-composites is also related to its accumulation, as shown in the microstructure Figure 5.

Because of the high-density reduction of graphene samples, the hot rolling process was performed at optimum sintering process conditions, $565^{\circ} \mathrm{C}$ for $60 \mathrm{~min}$. The hot rolling process was performed by a $35 \%$ reduction ratio to improve the densification by reducing the porosity and eliminating agglomeration. An improvement in the density of all samples is celebrated from the curve after rolling. The curve shows that the density of the $\mathrm{Al} / 10 \mathrm{Cu}$ is decreased by the addition of $2.5 \mathrm{Al}_{2} \mathrm{O}_{3}$ and the different percentages of graphene for reasons that may be related to their densities. The most remarkable improvement has been achieved at the $1.5 \mathrm{wt} \%$ GNs sample with a $6.61 \%$ increment, and the lowest improvement has been achieved for the $\mathrm{Al} / 10 \mathrm{wt} \% \mathrm{Cu}$ sample with $1 \%$ increment. The increase in the percentage of improvement by increasing the graphene ratio expresses the extent of enhancement in the internal structure and the elimination of defects that may have arisen from the accumulation of graphene flakes and their adhesion to each other, as the graphene flakes are characterized by a large surface area, which encourages this. It 
is expected that the rolling process led to the sliding of the graphene flakes over each other, thus improving their distribution within the microstructure and getting rid of any porosity and accumulations, which leads to the general improvement of the properties of the produced samples. Also, the rolling process causes a grain refinement which enhances the densification.

\subsection{Microstructure investigation}

The microstructure of the sintered Al nano-composites at $565^{\circ} \mathrm{C}$ for 60 min under a vacuum control atmosphere by the SEM (BSC) was investigated, as shown in Figure 5. An ideal microstructure has been achieved under the conditions mentioned above. The aluminum in the pure sample appears dark gray with no voids. No grain boundaries were detected, which means high purity and good control preparation process. White areas represent the copper in sample 2 that appears well and uniformly distributed due to the good mechanical alloy milling processes using the hexane lubricant for long periods of $45 \mathrm{hr}$. The hexane lubricant facilitated particles slipping so that agglomeration wasn't established. The milling process not only achieved good distribution for copper but also grain refining and diffusion were established. High harmony between aluminum and copper is observed, and the dendritic shape of the asreceived copper powder is refined and changed to semi sphere shape due to the long mechanical milling time. Because of the low magnification of images, the nano-alumina particles haven't been noted in sample (c). In the images, d, e, and f black spots representing graphene layers are detected. Regardless of the good distribution of the GNs, some accumulations were constituted by increasing their percentages. For the $1.5 \mathrm{GNs}$ sample, it is clear that the black spots that represent the GNs suffer from some agglomerations all over the Al matrix. This can be explained by the nature of GNs, which are a single layer with atomic thickness. It can be collected with each other's again by a covalent band when the percentage increases. The rolling process is suggested to enhance its distribution to avoid the drawback that may be happening in mechanical properties. In general, no porosities are observed in all microstructures.

Figure 6 shows the microstructure of the fabricated nanocomposites after the hot rolling process at 480 ${ }^{\circ} \mathrm{C}$ with a $35 \%$ reduction. Excellent distribution and adhesion of $\mathrm{Al}$ with the $\mathrm{Cu}$, nano- $\mathrm{Al}_{2} \mathrm{O}_{3}$, and $\mathrm{GNs}$ is observed. The hot rolling process participated in sliding the GNs layers, and its accumulations are dissipated, and grain refining was also established. The shape of the Cu particles is affected by the rolling process where it is elongated and diffused within the Al matrix. The high diffusion between $\mathrm{Al}$ and $\mathrm{Cu}$ particles encourage intermetallics formation that increases the strength on the grain boundaries [10]. Graphene flakes, which have a large surface area compared to their thickness, appeared horizontal in all samples. No cracks are noted on the grain boundaries of copper and graphene with aluminum due to heating rolled samples at moderate temperature $480^{\circ} \mathrm{C}$. An excellent distribution of the nano-alumina is appeared in images e and f. Due to the hot rolling process compression, both GNs and Cu particles have been flattened. The flattening increases their surface area, which increases their positive effects on the properties of the prepared samples. The nano-alumina particles embedded in the spaces between the copper grains and the graphene flakes, increasing the manufactured composites' strength and durability.

\subsection{Chemical composition analysis}


The phase composition and phase structure of the fabricated samples were investigated by the X-ray analysis, as shown in Figure 7. The Al pure sample is taken as a reference sample. For all samples, the mean peaks of the Al matrix appear with high intensity. Also, $\mathrm{Cu}$ and $\mathrm{Al}_{2} \mathrm{O}_{3}$ peaks are recorded, but the $\mathrm{Al}_{2} \mathrm{O}_{3}$ peak's intensity is small due to its small ratio and dissipated at samples $1 \mathrm{wt} \%$ and $1.5 \mathrm{wt} \%$. Carbon peaks that represent the GNs are observed. Its intensity is very weak due to its low percentage. It is increased by increasing the GNs content. As a result of reinforcing the Al reference sample by a $10 \% \mathrm{wt}$ $\mathrm{Cu}$, new intermetallic $\mathrm{Cu} \mathrm{Al}_{2}$ was formed. The $\mathrm{Al}-10 \% \mathrm{wt} \mathrm{Cu}$ chemical composition didn't change by adding $2.5 \mathrm{wt} \% \mathrm{Al}_{2} \mathrm{O}_{3}$ and different percentages of $\mathrm{GNs}(0.5-1.5 \% \mathrm{wt})$. The harmful aluminum carbide $\left(\mathrm{Al}_{4} \mathrm{C}_{3}\right)$ compound was not detected during the milling and sintering. Also no oxide or carbides were recorded due to the good control in the sintering process.

\subsection{Hardness measurement}

Figure 8 represents the hardness behavior of the powder metallurgy and hot-rolled Al samples. The powder metallurgy nanocomposites curve shows that the aluminum's hardness was increased by reinforcing it with 10 wt\% Cu from 82 to 93 with a $13.14 \%$ increment and from 93 to 122 due to reinforcing the $\mathrm{Al} / 10 \mathrm{Cu}$ with $2.5 \% \mathrm{Al}_{2} \mathrm{O}_{3}$ with $31.18 \%$. In the same way, the hardness of the $\mathrm{Al}-10 \mathrm{Cu} / 2.5$ $\mathrm{Al}_{2} \mathrm{O}_{3}$ increased by increasing the percentage of the graphene up to $1 \%$ from 122 to 278 , with an increment of $127.86 \%$, then it decreased to 218 at $1.5 \mathrm{wt} \% \mathrm{GNs}$. These improvements are initially due to additive properties, adhesion, and distribution with the Al matrix. Copper has 40HV, alumina has 15.7 $\mathrm{GPa}$, and the graphene has $100 \mathrm{GPa}$. Also, graphene has a unique mechanical and physical properties that made it used in many industrial applications. It is also characterized by its low density of $2.2 \mathrm{~g} / \mathrm{cm}^{3}$ which make it good candidate for light weight applications [9].

Not only the quantity, distribution, and adhesion of the reinforcement affect the hardness of the produced material, but also its orientation inside the matrix has a great effect. Graphene flakes have a large surface area compared to their thickness. Referring to the microstructure of the samples reinforced with graphene, the surface area of the graphene flakes has taken a horizontal position, which makes it good resistant to penetration of the hardness measuring tool. By increasing the percentage of graphene, dispersion occurs in the direction of the flakes as a result of accumulation, which causes the hardness to decrease again, as is evident from the $1.5 \%$ GNs aluminum sample.

To further improve the hardness of the samples manufactured by powder metallurgy, especially those containing high percentages of graphene, which showed a decrease in hardness, they undergo a hot rolling process with the previously mentioned percentages. The results show a clear improvement in the hardness values for all samples, starting from pure aluminum up to $1.5 \%$ graphene sample. This may be attributed to the grain refinement of the particles due to the rolling process, which enhances the hardness according to the Hall Petch equation [11-12].

The hardness of the aluminum increased after rolling from 82 to 118 with $43.9 \%$. For the sample reinforced with $10 \%$ copper, the hardness increased from 93 to 133 with $43 \%$. The hardness of the Al- 
$10 \mathrm{Cu}$ sample reinforced with $2.5 \mathrm{Al}_{2} \mathrm{O}_{3}$ increased from 122 to 178 with a 45.9 increment. The most significant improvement is established for $1.5 \mathrm{GNs}$, where the hardness of the $\mathrm{Al}-10 \mathrm{Cu}-2.5 \mathrm{Al}_{2} \mathrm{O}_{3}$ sample increased from 218 to 389 with a $78.4 \%$ increment. This achievement of $1.5 \mathrm{GNs}$ sample indicates the importance of conducting the hot rolling as a secondary process after powder metallurgy technique, as it contributes in particles refining, GNs redistribution, and getting rid of agglomerations and voids.

\subsection{Compressive strength measurements}

The behavior of the powder metallurgy and hot-rolled aluminum nanocomposites reinforced with $10 \mathrm{Cu}$, $2.5 \mathrm{Al}_{2} \mathrm{O}_{3}$, and different percentages of graphene nano-sheets under a uniaxial compression load is shown in Figures 9a and 9b, respectively. In the case of powder metallurgy, the compressive strength is increased gradually by strengthening aluminum with $10 \mathrm{Cu}, 2.5 \mathrm{Al}_{2} \mathrm{O}_{3}$, and different amounts of graphene up to $1 \mathrm{wt} \%$ then decreased for $1.5 \mathrm{GNs} \%$ sample. The compressive strength results agree with the hardness results shown in Figure 8 according to the equation driven by Tabor, where the strength of a material is directly proportional to the Vickers hardness value in $\mathrm{kg} / \mathrm{mm}^{2}$ by 3.33 factor [13].

The addition of $2.5 \mathrm{Al}_{2} \mathrm{O}_{3}$ to the $\mathrm{Al}-10 \mathrm{Cu}$ composite increases the strength from 1290 to $1350 \mathrm{MPa}$ with $4.65 \%$. The $\mathrm{Al}_{2} \mathrm{O}_{3}$ is a ceramic material with a good strength so, dispersing it in a malleable material such as $\mathrm{Al}$ gives it strength and enhances the mechanical properties [8]. On the other hand, reinforcing the Al$10 \mathrm{Cu} / 2.5 \mathrm{Al}_{2} \mathrm{O}_{3}$ with $1 \mathrm{wt} \% \mathrm{GN}$ improves the strength by $52.59 \%$, increasing from 1350 to $2060 \mathrm{MPa}$. This increment is due to the high strength of graphene transferred to the Al matrix due to its good distribution and adhesion. Because graphene has a large surface area, it effectively prevents the growth and movement of dislocations in the aluminum matrix and consequently increases the strength [14]. The restriction of dislocation may be related to the orientation of graphene inside the aluminum matrix. The turbulent ordination of graphene layers can make a complex internal resistance and consequently increases the resistance of a material to externally applied forces.

Decreasing the compressive strength at $1.5 \% \mathrm{GNs}$ may be due to the production of accumulations that facilitate the slip of particles over each other and consequently reduce the strength of the material. Also, these agglomerations create pores inside the matrix, which decreases the compression strength as the internal voids act as a center for crack propagation. Tian, Wen-ming, et al. [15] studied the effect of graphene with 1, 2, $3 \mathrm{wt} \%$ on the structure and mechanical properties of 7055 aluminum matrix composites prepared by the spark plasma sintering. The results showed that the composites' hardness and compressive strength were improved with the addition of $1 \mathrm{wt} \%$ graphene. A clean, robust interface is formed between the metal matrix and graphene via metallurgical bonding on the atomic scale. The addition of graphene above $1 \mathrm{wt} \%$ results in the deterioration in mechanical properties of the composites. The accumulation of graphene plates is exacerbated by increasing graphene content, which is the main reason for this deterioration.

The same trend of materials compressive strength is observed after the hot rolling process. Due to the reduction in porosity and excellent distribution of accumulated graphene layers, all results are improved 
up to $1.5 \mathrm{wt} \% \mathrm{GNs}$. Some changes were observed in the behavior of samples after the rolling process, where the yield strength and the maximum compressive strength are increased. The linear slop relationship between the stress and strain in the elastic regions is improved, which means increasing the stiffness of the $\mathrm{Al}$ matrix nanocomposite. The strength of the $\mathrm{Al}-10 \mathrm{Cu}-2.5 \mathrm{Al}_{2} \mathrm{O}_{3}$ sample is increased by adding $1 \mathrm{wt} \%$ GNs from 1580 to $2470 \mathrm{MPa}$ with $56.32 \%$ after hot rolling compared with $52.59 \%$ for the same powder metallurgy sample. The $1.5 \mathrm{wt} \% \mathrm{GNs}$ rolled model achieved $57.6 \%$ improvement compared with $35.55 \%$ for the same powder metallurgy sample. A $22 \%$ improvement in the $1.5 \% \mathrm{GNs}$ sample after the hot rolling process is achieved.

\subsection{Wear test}

The results of the adhesive wear test at different loads of 5 and $10 \mathrm{~N}$ and different rotational speeds of 200, 300, $400 \mathrm{rpm}$ for $10 \mathrm{~min}$ at room temperature are shown in Figure 10. Four phenomena can be deduced from the results. The first is the effect of copper, alumina, and different ratios of graphene on the wear rate of aluminum, which indicates that the addition of these elements led to an improvement in the wear resistance up to $1 \mathrm{wt} \% \mathrm{GNs}$ for sintered samples and up to $1.5 \mathrm{wt} \% \mathrm{GNs}$ for hot-rolled samples. In general, this can be attributed to the good mechanical properties of these elements. GNs are a lubricant material with low density, so it is floated on the surface of the Al nanocomposite and form a tribo-layer that helps in sliding the wear pin on the surface without losing weight. The decrease in the wear rate of $1.5 \mathrm{wt} \% \mathrm{GNs}$ for the sintered samples is mainly due to the accumulation of graphene, which causes a decrease in the hardness and, consequently, decreases its resistance to material loss. The presence of accumulations leads to the ease of slipping the graphene sheets over each other, thus increasing the amount of weight loss resulting from the friction. By conducting the rolling process, the accumulations in the sample of $1.5 \%$ were disappeared, as shown in the microstructure of rolled samples. Also, the grain particles were refined, which improves the sample's resistance to erosion and thus reduced the wear rate. The second is how this characteristic is affected by the rolling process, which showed that the wear rate is decreased significantly after the rolling process. The third phenomenon is the impact of applied load on the wear rate, which is gradually increased with the increase in the applied load. Increasing the load leads to an increase in the contact area and thus the friction between the pairs' surfaces, which leads to a rise in the temperature and plasticizing the surface of the sample, thus increasing the rate of wear. Finally, the influence of sample sliding speeds on the wear rate showed that the wear rate gradually increased by increasing the speed at all loads. This increment can be attributed to the increase in contact path length and contact time, which give a significant chance for wear.

\section{Conclusion}

In this paper, six aluminum based samples in the form of powder, which are pure aluminum, $\mathrm{Al} / 10 \% \mathrm{Cu}$, $\mathrm{Al}-10 \% \mathrm{Cu} / 2.5 \% \mathrm{Al}_{2} \mathrm{O}_{3}, \mathrm{Al}-10 \% \mathrm{Cu}-2.5 \mathrm{Al}_{2} \mathrm{O}_{3} / \mathrm{GNs}(0.5,1$, and $1.5 \mathrm{wt} \%)$ were manufactured using powder metallurgy technique and hot rolling as a secondary process. All samples were mixed for 45 hours using mechanical alloy milling, then pressed at $600 \mathrm{MPa}$ and heated in a vacuum oven at $565^{\circ} \mathrm{C}$ for 60 minutes. Heating rates were between 2 to $4^{\circ} \mathrm{C} / \mathrm{min}$. The sintered and rolled samples were examined by 
studying the chemical composition, microstructure, relative density, hardness, compressive strength, mechanical wear, and electrical conductivity. The results are summarized in the following points.

1. The optimum conditions for sample production by powder metallurgy were $600 \mathrm{MPa}$ and $565^{\circ} \mathrm{C}$ for an hour.

2. The microstructure of the samples produced by powder metallurgy method showed a good distribution of elements with some accumulations of graphene layers.

3. The microstructure of the rolled samples showed a perfect distribution of all elements with the disappearance of graphene flakes accumulations, the absence of any pores, and good coalescence with the Al base metal and other elements.

4. The X-ray chemical analysis showed the formation of $\mathrm{CuAl}_{2}$ inter-metallic between aluminum and copper, and no foreign elements were detected. No interaction between aluminum and graphene to form the $\mathrm{Al}_{4} \mathrm{C}_{3}$ aluminum carbide compound has been established.

5. The relative density of the samples generally improved after the rolling process due to the disposal of graphene flakes accumulations, and consequently, the disappearance of the internal pores between those layers.

6. The hardness of aluminum samples produced by the powder metallurgy method was improved by adding copper, alumina, and graphene up to $1 \%$ and then degraded at $1.5 \%$.

7. The deterioration in the $1.5 \%$ hardness sample improved after the rolling process by $78.4 \%$, resulting from getting rid of any accumulations or internal pores.

8. The compressive strength and stiffness of the Al samples were improved by adding copper, alumina, and graphene after the rolling process due to the particles' refinement and the elimination of defects in the samples produced by the powder metallurgy method.

9. The wear rate of the Al was decreased by adding copper and alumina due to the formation of intermetallic compounds and the high hardness of alumina. The unique mechanical properties of graphene and its accumulation on the surface facilitate the slip process between the friction pairs and reduce the wear rate. In general, the results improved significantly after the rolling process, especially at $1.5 \%$ graphene.

\section{Declarations}

\section{Funding}

No funding was received from any organization or person for this work.

\section{Acknowledgement}


Authors wish to thank technical staff of production technology department-Faculty of Technology and Education - Helwan University, and Powder Technology Department, Manufacturing Technology institute, CMRDI, Egypt, Cairo, Egypt, for their cooperation

Conflict of interest (No Conflict of interest with any organization or person)

Availability of data and material (data transparency)

Not applicable

Code availability (software application or custom code)

Not applicable

Ethics approval (include appropriate approvals or waivers)

Not applicable

Consent to participate (include appropriate statements)

Not applicable

Consent for publication (include appropriate statements)

Not applicable

\section{References}

1. Zhang ZW, Liu ZY, Xiao BL, Ni DR, Ma ZY (2018) High Efficiency Dispersal and Strengthening of Graphene Reinforced Aluminum Alloy Composites Fabricated by Powder Metallurgy Combined with Friction Stir Processing. Carbon 135:215-223

2. Zhou W, Mikulova P, Fan Y, Kikuchi K, Nomura N, Kawasaki A (2019) Interfacial Reaction Induced Efficient Load Transfer in Few-Layer Graphene Reinforced Al Matrix Composites for HighPerformance Conductor. Composites Part B 167:93-99

3. Wu Y, Zhan K, Yang Z, Sun W, Zhao B, Yan Y, Yang J (2019) Graphene Oxide/Al Composites with Enhanced Mechanical Properties Fabricated by Simple Electrostatic Interaction and Powder Metallurgy. J Alloys Compd 775:233-240

4. Wen-ming Tian Song-mei, Li B, Wang X, Chen Jian-hua, Liu, Yu M (2016) Graphene-reinforced aluminum matrix composites prepared by spark plasma sintering, International Journal of Minerals, Metallurgy and Materials Volume 23, Number 6, June Page 723

5. Latief FH, El-Sayed M, Sherif AA, Almajid H, Junaedi (2011) Fabrication of exfoliated graphite nanoplatelets-reinforced aluminum composites and evaluating their mechanical properties and corrosion behavior, Journal of Analytical and Applied Pyrolysis, Volume 92, Issue 2, Pages485-492 
6. Xie Y, Meng X, Mao D, Qin Z (2021) Long Wan, and Yongxian Huang. Homogeneously Dispersed Graphene Nanoplatelets as Long-Term Corrosion Inhibitors for Aluminum Matrix Composites ACS Appl Mater Interfaces 13:32161-32174

7. Lokesh GN, Ramachandra M, Mahendra KV (2014) Effect of Hot Rolling on Al-4.5\%Cu Alloy Reinforced Fly Ash Metal Matrix Composite. International Journal of Composite Materials 4(1):2129

8. Hossam M, Yehia S, Allam (2021) Hot Pressing of Al-10 wt\% Cu-10 wt\% Ni/x ( $\left(\mathrm{Al}_{2} \mathrm{O}_{3}-\mathrm{Ag}\right)$ Nanocomposites at Different Heating Temperatures. journal of Metals and Materials International volume 27:500-513

9. Hossam M, Yehia F, Nouh O, El-Kady (2018) Effect of graphene nano-sheets content and sintering time on the microstructure, coefficient of thermal expansion, and mechanical properties of (Cu /WC eTiC-Co) nano-composites". J Alloys Compd 764:36e43

10. Yunya, Zhang et al (2019) Bioinspired, graphene-enabled Ni composites with high strength and toughness. Sci Adv 5:eaav5577.10.1126/sciadv.aav5577

11. Hassan M, Yehia H, Mohamed A, El-Nikhaily A, Elkady O Effect of Copper Addition on the AlCoCrFeNi High Entropy Alloys Properties via the Electroless Plating and Powder Metallurgy Technique.Crystals2021, 11,540, https://doi.org/10.3390/cryst11050540.

12. Yehia HM, El-Tantawy A, Ghayad I, Eldesoky AS, El-Kady O (2020) Effect of zirconia content and sintering temperature on the density, microstructure, corrosion, and biocompatibility of the Ti-12Mo matrix for dental applications. J Mater Res Technol 9:8820-8833

13. Yehia HM (2019) Microstructure, physical and mechanical properties of the Cu/ (WC-TiC-Co) nanocomposites by the electro-less coating and powder metallurgy technique. J Compos Mater 53:19631971

14. Butz B, Dolle C, Niekiel F, Weber K, Waldmann D, Weber HB Bernd Meyer\& Erdmann Spiecker, Dislocations in bilayer graphene,NATURE, VOL 505,533-537

15. Wen-ming Tian Song-mei, Li B, Wang X, Chen Jian-hua, Liu, Yu M (2016) Graphene-reinforced aluminum matrix composites prepared by spark plasma sintering, International Journal of Minerals, Metallurgy and Materials, Volume 23, Number 6, June Page 723, DOI: 10.1007/s12613-016-1286-0

\section{Figures}




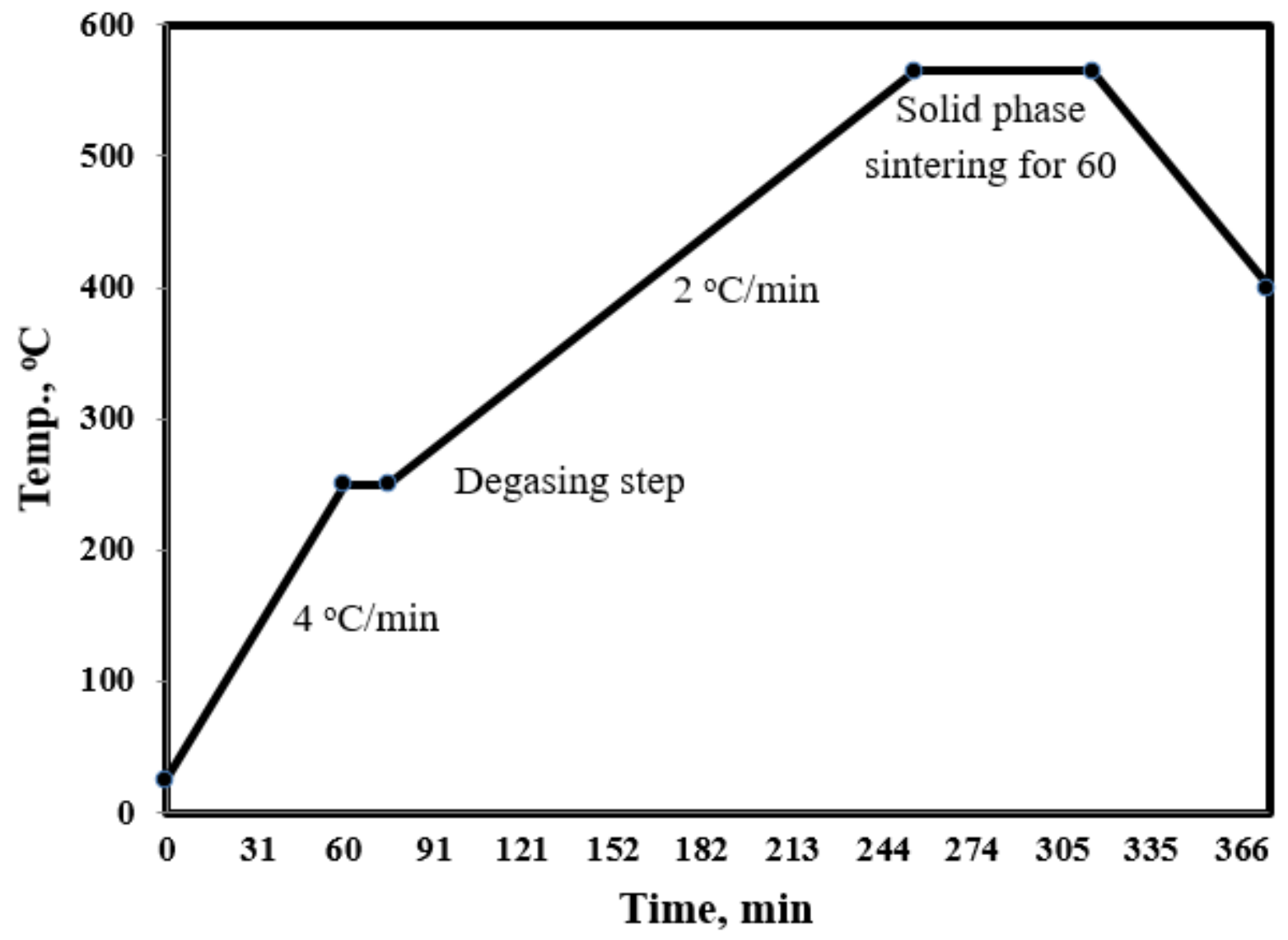

Figure 1

The sintering cycle curve of $\mathrm{Al}-\mathrm{Cu}-\mathrm{Al}_{2} \mathrm{O}_{3} / \mathrm{Gr}$ nano composites at $565^{\circ} \mathrm{C}$ for $60 \mathrm{~min}$.

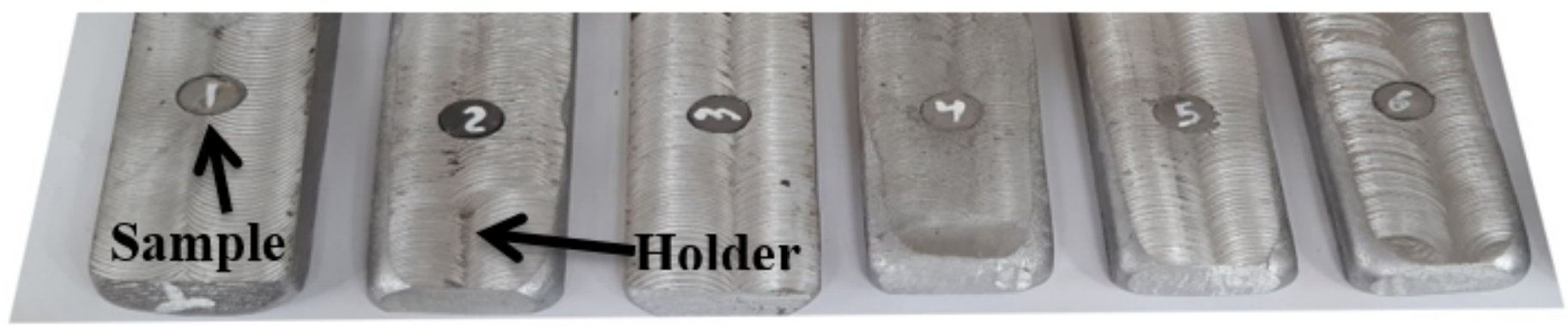

Figure 2

The shape of samples equipped with aluminum stand for the rolling process 

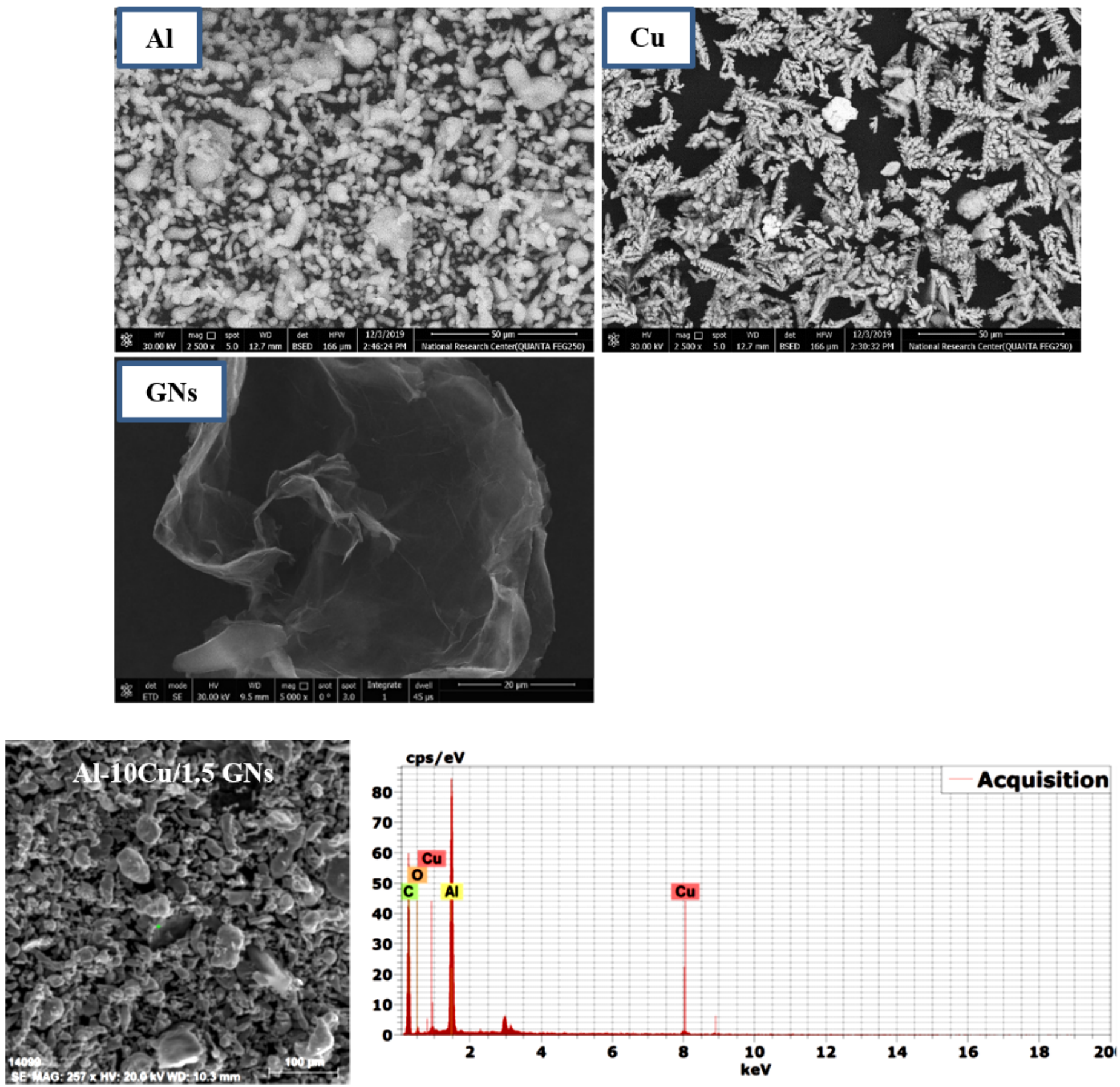

\section{Figure 3}

SEM (BSE) and EDX analysis of as-received powder, and the Al-10Cu/1.5 \%wt GNs powder nanocomposite 


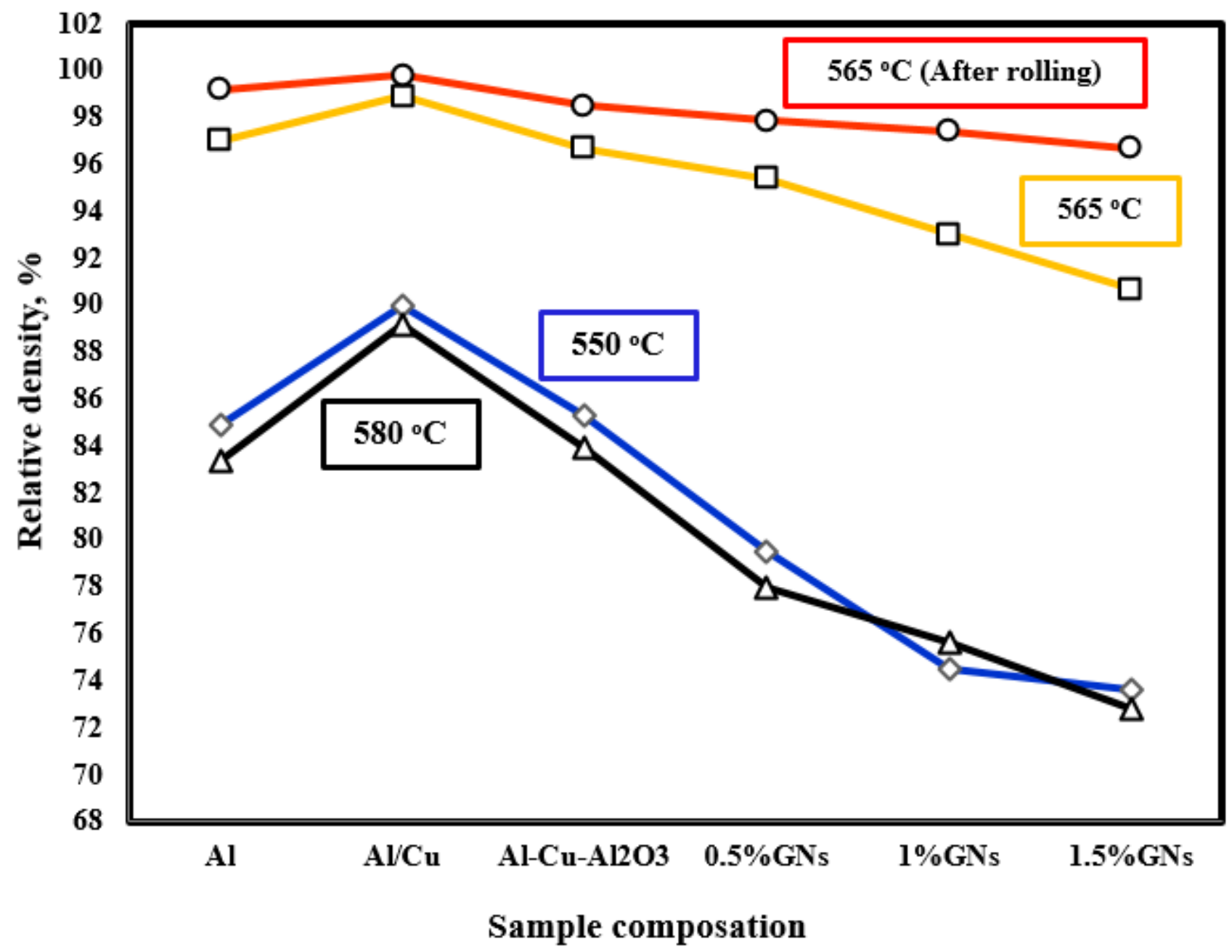

Figure 4

The relative density of the powder metallurgy and hot rolled samples 


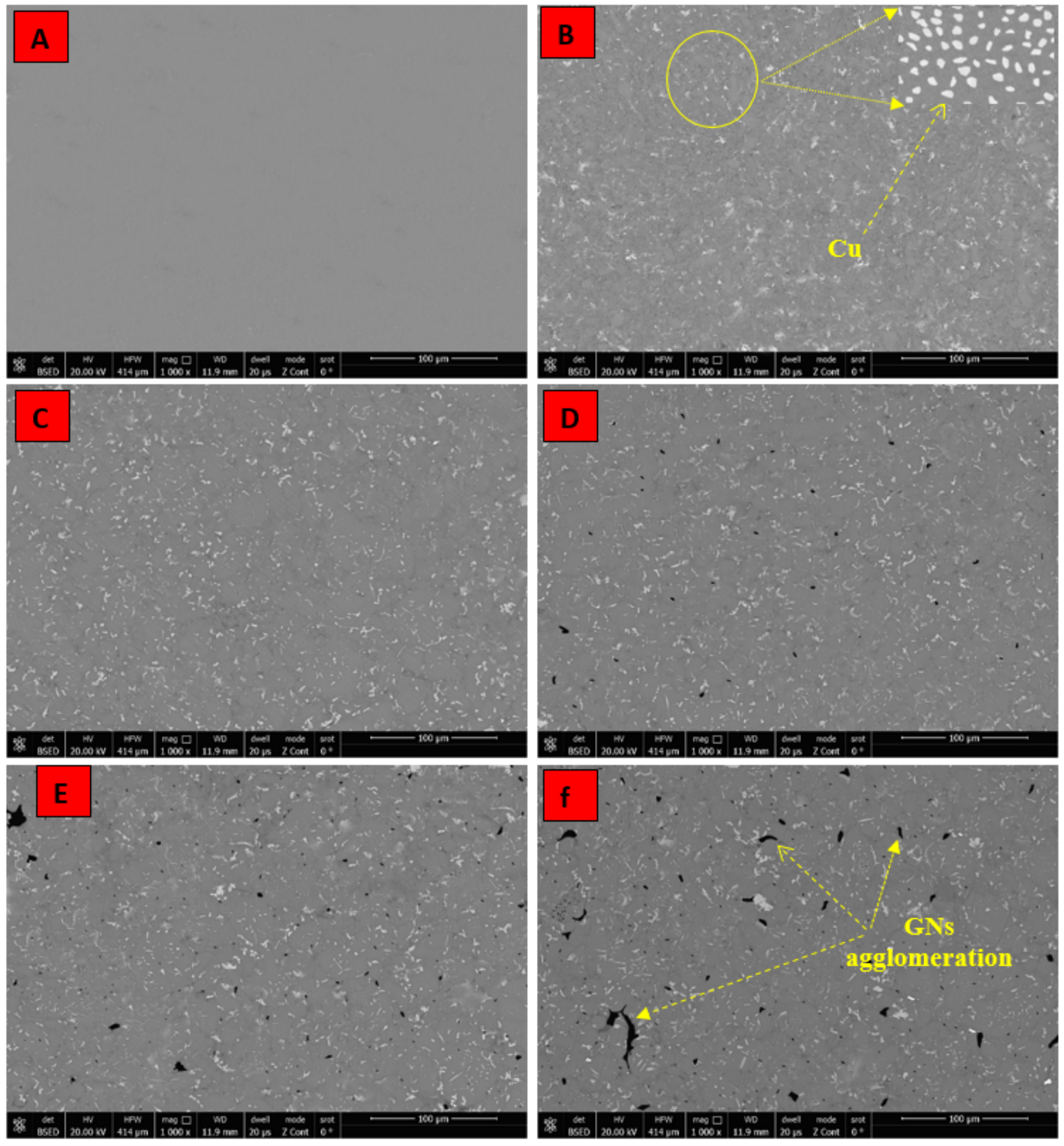

Figure 5

Microstructures of sintered samples at $565^{\circ} \mathrm{C}$ for $60 \mathrm{~min}$, (A) pure Al, (B) Al/10\% Cu, (C) Al-10\%Cu/ 2.5\% $\mathrm{Al}_{2} \mathrm{O}_{3}$, (D) $0.5 \mathrm{wt} \% \mathrm{GNs}$, (E) $1 \mathrm{wt} \% \mathrm{GNs}$, (f) $1.5 \mathrm{wt} \% \mathrm{GNs}$. 


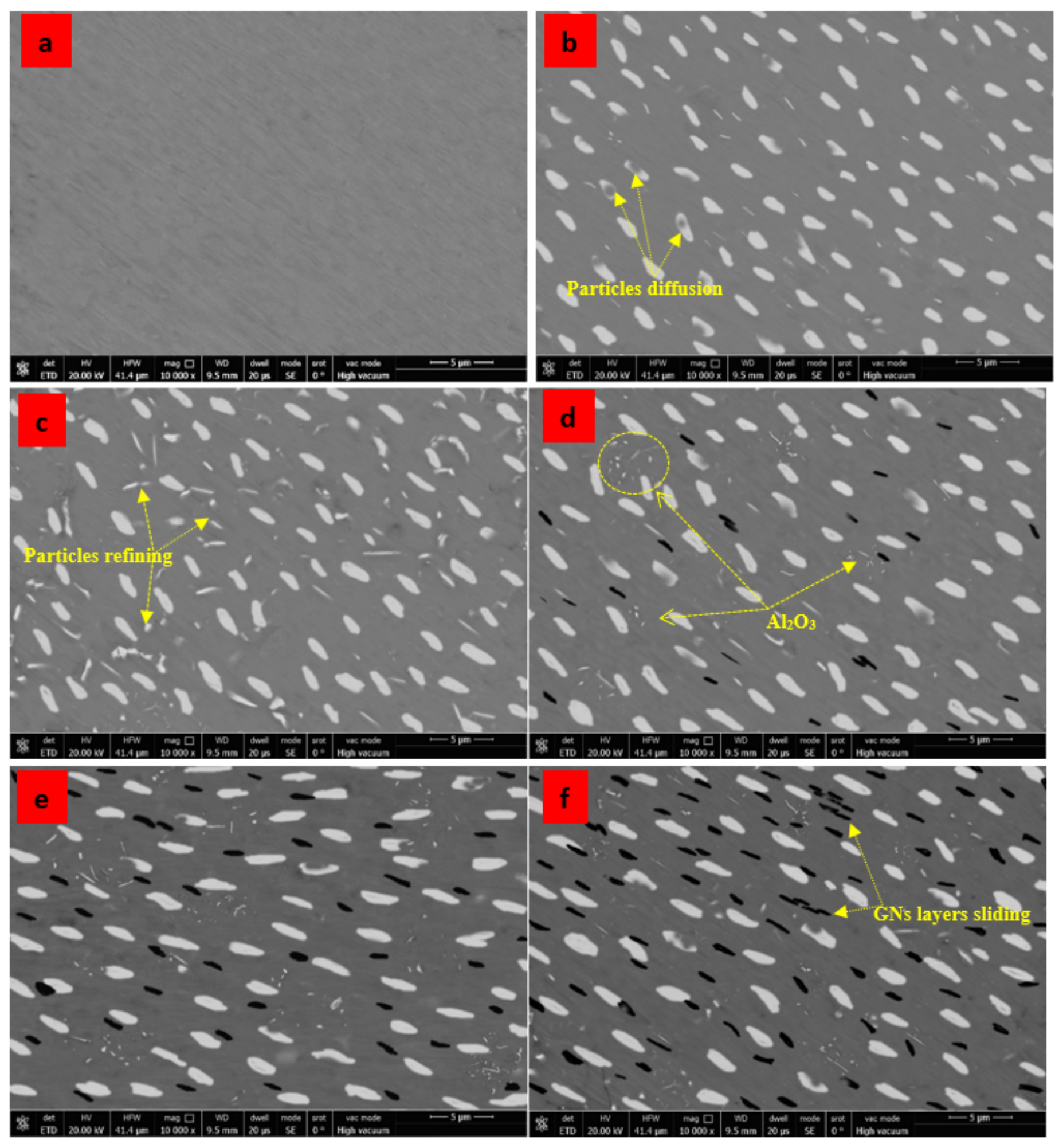

Figure 6

The microstructure of rolled samples 


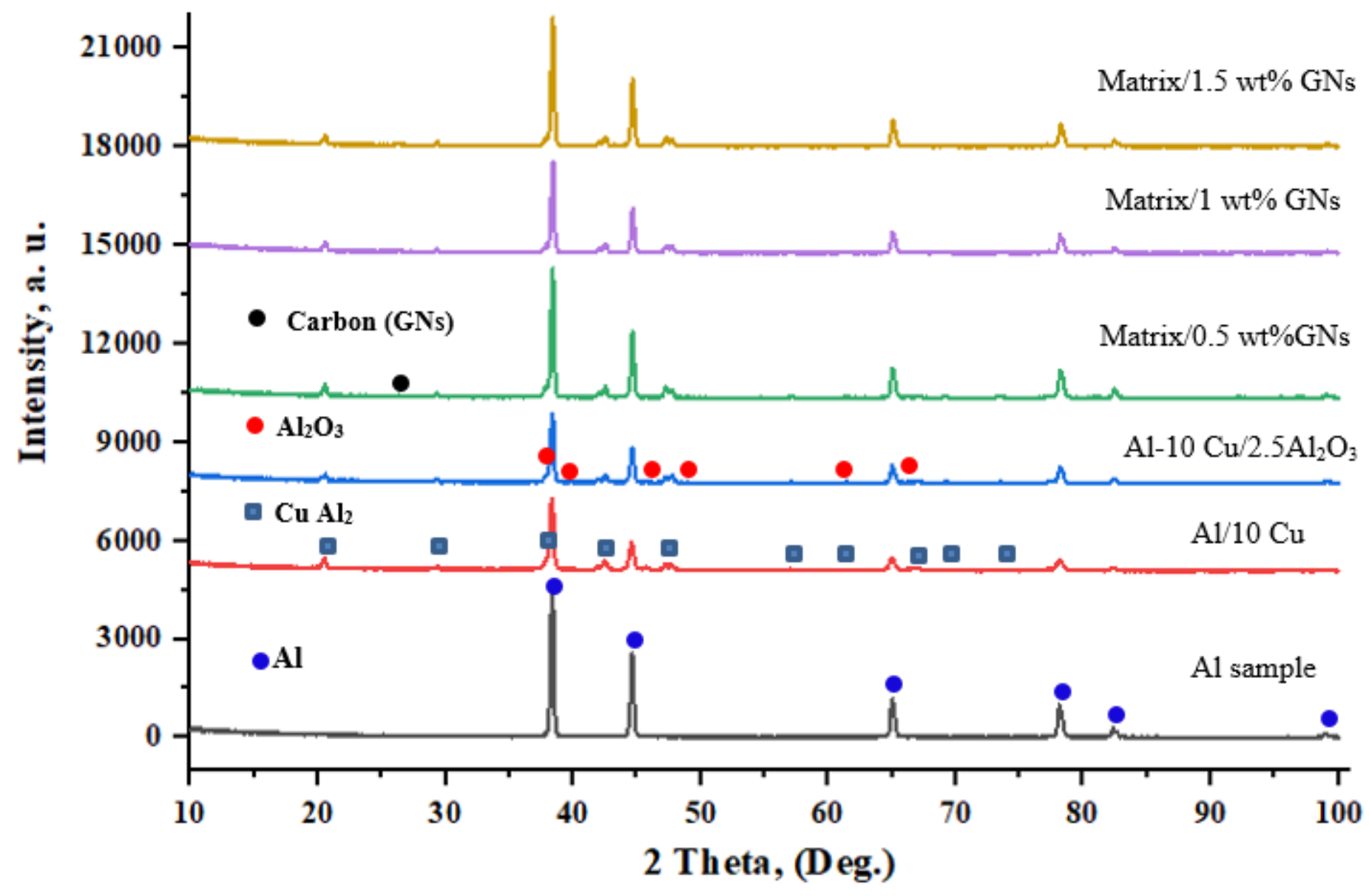

Figure 7

XRD patterns of Al-10Cu-2.5 $\mathrm{Al}_{2} \mathrm{O}_{3} / \mathrm{xGNs}$ nano-composites sintered samples. 


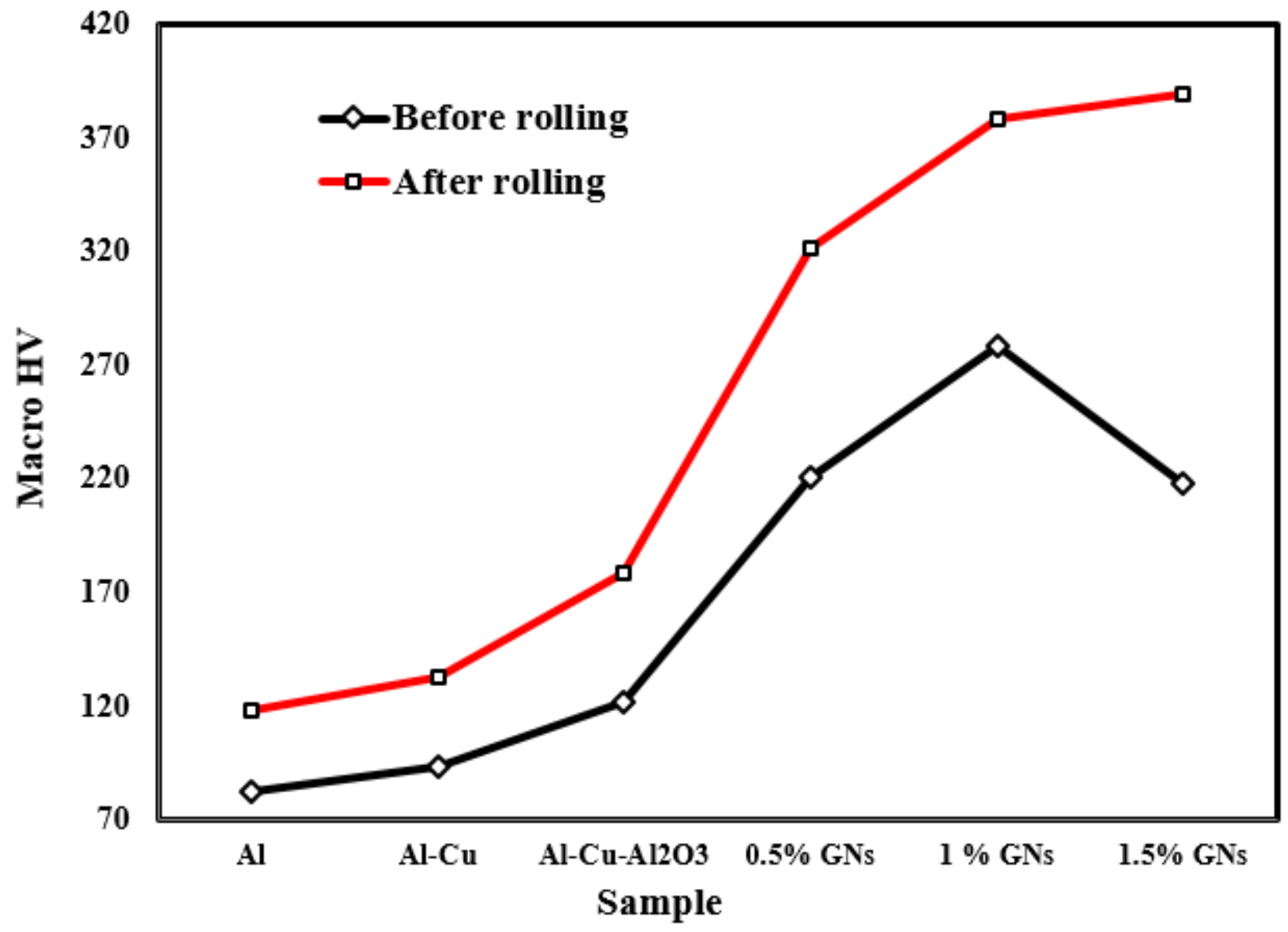

Figure 8

Macro-hardness measurements of the nanocomposites before and after rolling
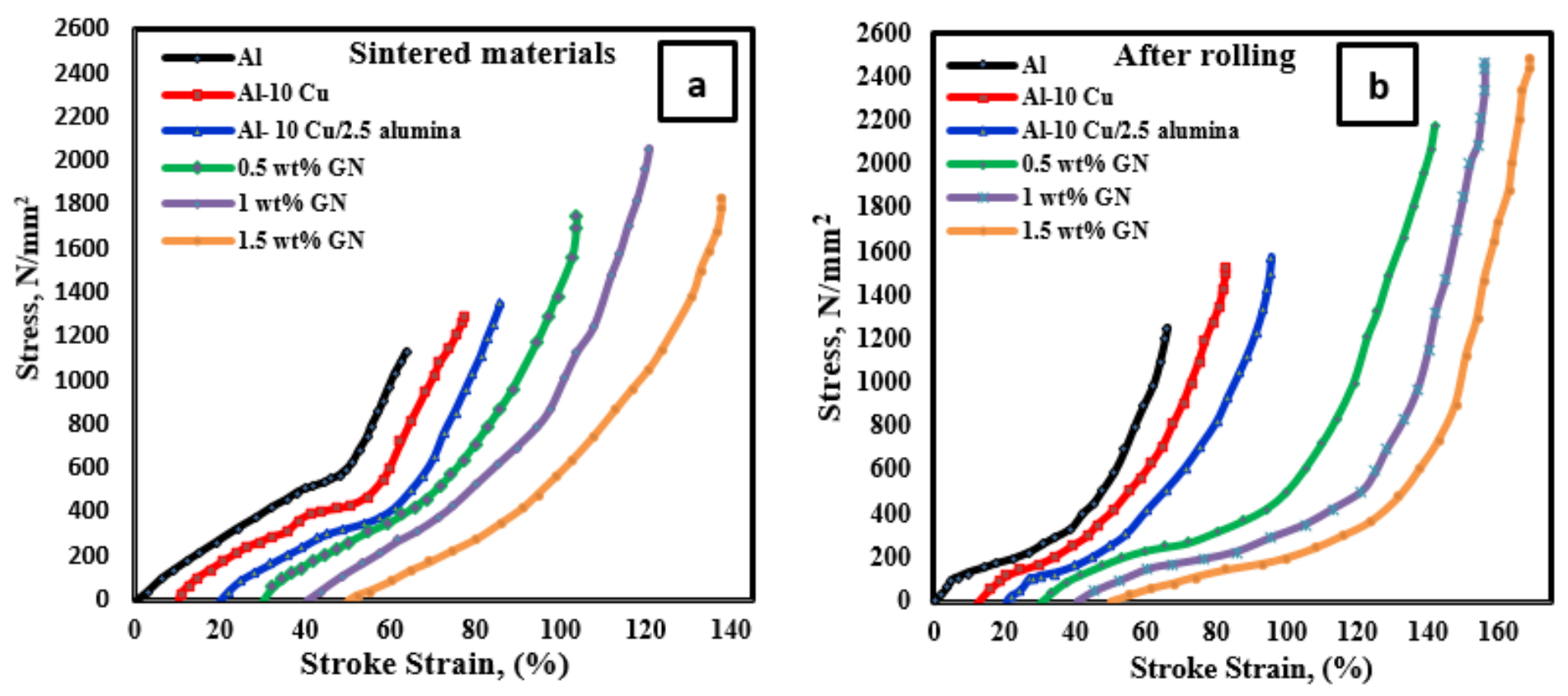
Figure 9

Stress-stain curves of the nanocomposites before and after rolling
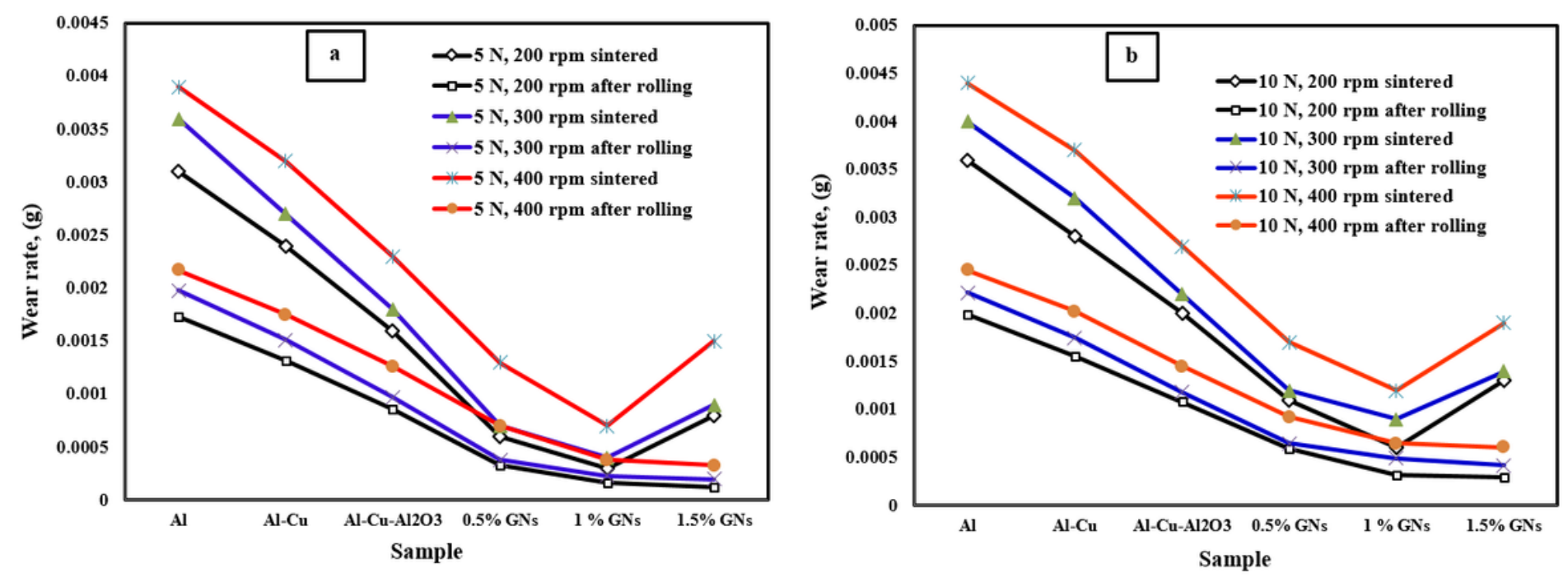

Figure 10

Adhesive wear test results at different loads ( 5 and $10 \mathrm{~N})$ and different rotational speeds $(200,300$, and $400 \mathrm{rpm})$ 